\title{
SCIENTIFIC REPORTS

\section{OPEN Nrf2 positively regulates autophagy antioxidant response in human bronchial epithelial cells exposed to diesel exhaust particles}

\author{
Daniela Perroni Frias ${ }^{1 *}$, Raquel Labiapari Nunes Gomes ${ }^{1}$, Kelly Yoshizaki ${ }^{1}$, \\ Regiani Carvalho-Oliveira' ${ }^{1}$, Monique Matsuda ${ }^{2}$, Mara de Souza Junqueira ${ }^{3}$, \\ Walcy Rosolia Teodoro ${ }^{4}$, Pérola de Castro Vasconcellos ${ }^{5}$, Daniela Cristina de Almeida Pereira ${ }^{5}$, \\ Paulo Roberto da Conceição ${ }^{6}$, Paulo Hilário Nascimento Saldiva ${ }^{1}$, Thais Mauad ${ }^{1}$ \& \\ Mariangela Macchione ${ }^{1}$
}

Diesel exhaust particles (DEP) are known to generate reactive oxygen species in the respiratory system, triggering cells to activate antioxidant defence mechanisms, such as Keap1-Nrf2 signalling and autophagy. The aim of this study was to investigate the relationship between the Keap1-Nrf2 signalling and autophagy pathways after DEP exposure. BEAS-2B cells were transfected with silencing RNA (siRNA) specific to Nrf2 and exposed to DEP. The relative levels of mRNA for Nrf2, NOO1, HO-1, LC3B, p62 and Atg 5 were determined using RT-PCR, while the levels of LCB3, Nrf2, and p62 protein were determined using Western blotting. The autophagy inhibitor bafilomycin caused a significant decrease in the production of Nrf2, $\mathrm{HO}-1$ and $\mathrm{NOO} 1$ compared to DEPs treatment, whereas the Nrf2 activator sulforaphane increased the LC3B $(p=0.020)$ levels. BEAS-2B cells exposed to DEP at a concentration of $50 \mu \mathrm{g} / \mathrm{mL}$ for $2 \mathrm{~h}$ showed a significant increase in the expression of LC3B $(p=0.001), p 62(p=0.008)$, Nrf2 $(p=0.003)$, HO-1 $(p=0.001)$ and NOO1 $(p=0.015)$ genes compared to control. In siRNAtransfected cells, the LC3B $(p<0.001), p 62(p=0.001)$ and Atg5 $(p=0.024)$ mRNA levels and the $p 62$ and LC3II protein levels were decreased, indicating that Nrf2 modulated the expression of autophagy markers $(R<1)$. These results imply that, in bronchial cells exposed to DEP, the Nrf2 system positively regulates autophagy to maintain cellular homeostasis.

Chronic exposure to air pollution has been associated with adverse effects on the health of individuals ${ }^{1}$, such as inflammation ${ }^{2-4}$ and mucociliary clearance dysfunction ${ }^{5}$ of the respiratory system. Air pollution particulate matter (PM) induces oxidative stress in airway tissues, causing living organisms to activate their defences to prevent cell death ${ }^{6-8}$. One mechanism that cells use for defence against oxidative stress is autophagy, which is a homeostatic process that reduces cytoplasmic volume by degrading damaged organelles and proteins through a lysosome-dependent degradation process, and new organelles and proteins are synthesized as replacements ${ }^{9-11}$. Previous studies have emphasized that exposure to PM induces the generation of reactive oxygen species (ROS) and increases the levels of autophagy and cell death ${ }^{12-14}$.

Some of the most harmful components of urban PM are derived from diesel exhaust particles (DEP) ${ }^{15,16}$. Usually, composed of carbon nuclei, DEP have large surface areas that can adsorb other chemicals in the

\footnotetext{
${ }^{1}$ Laboratory of Experimental Air Pollution (LIM-05), Department of Pathology, School of Medicine, University of São Paulo, Av. Dr. Arnaldo 455, São Paulo, Brazil. ² Laboratory of Investigation in Ophthalmology (LIM-33), Division of Ophthalmology, School of Medicine, University of São Paulo, Av. Dr. Arnaldo 455, São Paulo, Brazil. ${ }^{3}$ Center for Translational Research in Oncology (LIM24), Cancer Institute of the State of São Paulo, Hospital das Clínicas (HCFMUSP) School of Medicine, University of São Paulo, Av. Dr. Arnaldo, 251, São Paulo, SP, Brazil. ${ }^{4}$ Rheumatology Division of the Hospital das Clinicas da Faculdade de Medicina da Universidade de Sao Paulo FMUSP, São Paulo, SP, BR, Av. Dr. Arnaldo, 455, room 3124, Cerqueira César, São Paulo, SP, 01246-903, Brazil. ${ }^{5}$ Chemistry Institute, University of São Paulo, São Paulo, Brazil. ${ }^{6}$ Physicist. Researcher of clean energy alternatives and clean mobility. Inventor and freelancer of Laboratory of Experimental Air Pollution in University of São Paulo, São Paulo, Brazil. *email: danielapfrias@usp.br
} 


\begin{tabular}{|l|l|l|l|}
\hline Element & EDX & Element & EDX \\
\hline $\mathrm{Cr}$ & $16,14 \pm 11,20$ & $\mathrm{Ba}$ & $24,78 \pm 15,68$ \\
\hline $\mathrm{Mn}$ & $22,62 \pm 1,34$ & $\mathrm{~Pb}$ & $2,29 \pm 1,60$ \\
\hline $\mathrm{Fe}(\%)$ & $0,29 \pm 0,00$ & $\mathrm{Na}(\%)$ & $0,21 \pm 0,03$ \\
\hline $\mathrm{Co}$ & $79,85 \pm 5,47$ & $\mathrm{Mg}$ & $3,99 \pm 6,06$ \\
\hline $\mathrm{Ni}$ & $3,27 \pm 1,73$ & $\mathrm{Al}$ & $0,67 \pm 0,58$ \\
\hline $\mathrm{Cu}$ & $14,09 \pm 1,15$ & $\mathrm{Si}$ & $338,24 \pm 17,07$ \\
\hline $\mathrm{Zn}$ & $285,21 \pm 0,51$ & $\mathrm{P}$ & $318,49 \pm 3,89$ \\
\hline $\mathrm{As}$ & $2,94 \pm 1,59$ & $\mathrm{~S}(\%)$ & $0,27 \pm 0,00$ \\
\hline $\mathrm{Br}$ & $2,05 \pm 1,30$ & $\mathrm{~K}$ & $73,29 \pm 2,51$ \\
\hline $\mathrm{Rb}$ & $1,35 \pm 0,59$ & $\mathrm{Ca}(\%)$ & $0,18 \pm 0,00$ \\
\hline $\mathrm{Zr}$ & $1,43 \pm 0,38$ & $\mathrm{Sc}$ & $150,03 \pm 3,97$ \\
\hline $\mathrm{Cd}$ & $1,01 \pm 0,01$ & $\mathrm{Cl}$ & $5,20 \pm 1,36$ \\
\hline
\end{tabular}

Table 1. Elementary compounds of DEP. The quantity of elements is calculated in ppm (part per million), except those indicated by “\%”. The values presented are mean \pm SEM (standard error mean).

environment, such as polycyclic aromatic hydrocarbons (PAHs), sulphate, nitrate, metals, carbon monoxide, aldehydes and various low molecular weight hydrocarbons ${ }^{17,18}$. PAHs and their derivatives are especially important because they are able to generate ROS in tissues ${ }^{19}$.

Genes encoding key antioxidant enzymes are important for maintaining intracellular redox homeostasis through the antioxidant response element (ARE) found within the promoter regions of these genes ${ }^{20}$. The transcription factor nuclear factor erythroid-derived 2-like 2 (NFE2L2, also known as Nrf2) induces ARE genes as part of a protective response against oxidative challenge to organelles and macromolecules ${ }^{21}$.

Recent in vivo and in vitro models have shown that the oxidative damage caused by PM exposure can activate the Nrf2-antioxidant response element signalling pathway ${ }^{22,23}$. Additionally, A549 cell and murine alveolar macrophage cultures exposed to DEP have shown increased Nrf2 and HO-1 (an Nrf2 target gene) expression levels ${ }^{24}$.

There is evidence that some autophagy genes, such as Atg5, Atg4D and SQSTM1/p62, have ARE promoter regions, and these promotors may be regulated through $\mathrm{Nrf} 2$ activity ${ }^{25}$. Nrf2 is normally present in the cytoplasm attached to Kelch-like ECH-associated protein 1 (Keap1), which facilitates the ubiquitination and proteolysis of Nrf2. In addition, protein p62 interacts with the same binding site as that of Nrf2-Keap1 and competitively inhibits the Keap1-Nrf2 interaction. The accumulation of p62 within the cells allows it to interact with Keap1 more frequently, resulting in the inhibition of Keap1 and, consequently, the activation of Nrf2 ${ }^{26,27}$. Also, p62 has been found to be a mediator in the formation of protein aggregates for autophagy recycling, functioning as an adapter for facilitating the binding of ubiquitinated protein aggregates and delivering them to autophagosomes, by associating with LC3 (protein light chain 3) a protein in autophagosome membrane ${ }^{28}$

The aim of this study was to examine the role of DEP in the Nrf2/ARE-mediated oxidant response and the influence of this pathway on the induction of autophagy in the human BEAS-2B bronchial cell line.

\section{Results}

DEP characterization. To verify the composition of the DEP collected, two characterization assays were performed: EDX (X-ray fluorescence by the energy dispersive method) to determine elements that comprise the DEP (Table 1); high-performance liquid chromatography to separate the PAH fractions and their derivatives; and gas chromatography in conjunction with mass spectrometry (GC/MS) was chosen for identification and quantification (Table 2). The results show high concentrations of PAH and metals in the DEP sample.

DEP cause disruptions to the respiratory chain and reduce cell viability. To ensure that the concentration of the DEP to be used in subsequent experiments did not cause a high death rate among the BEAS-2B cells, we performed MTT and Trypan blue tests. The MTT test is a measure of metabolic activity, while the Trypan blue test is a direct measure of the cell death rate. The results of the MTT assay showed that DEP exposure significantly reduced formazan absorbance, with significant differences between the $20 \mathrm{~min}$ and $2 \mathrm{~h}$ groups $(\mathrm{p}=0.009)$ and between the 1 and $2 \mathrm{~h}$ groups $(\mathrm{p}=0.01)$ (Fig. 1A). The results of the Trypan blue assay indicate that exposure to $50 \mu \mathrm{g} / \mathrm{mL}$ DEP significantly increased the percentage of dead cells compared to the number in the control $(\mathrm{p}=0.007)$ and $10 \mu \mathrm{g} / \mathrm{mL}(\mathrm{p}=0.015)$ groups. Additionally, exposure to $100 \mu \mathrm{g} / \mathrm{mL} \mathrm{DEP}$ concentration for $2 \mathrm{~h}$ increased the percentage of dead cells among all groups: $100 \mu \mathrm{g} / \mathrm{mL}$ vs. the control ( $\mathrm{p}=0.009) ; 100 \mu \mathrm{g} / \mathrm{mL}$ vs. $10 \mu \mathrm{g} /$ $\mathrm{mL}(\mathrm{p}=0.010) ; 100 \mu \mathrm{g} / \mathrm{mL}$ vs. $50 \mu \mathrm{g} / \mathrm{mL}(\mathrm{p}=0.025)$ (Fig. 1B). Taken together, these results allowed the decision for the concentrations of $10 \mu \mathrm{g} / \mathrm{mL}$ and $50 \mu \mathrm{g} / \mathrm{mL}$, which did not show a greater than $30 \%$ reduction in cell viability.

DEP increase the mRNA expression of both autophagic and antioxidant genes. The cells were exposed to DEPs at 10 and $50 \mu \mathrm{g} / \mathrm{mL}$ concentrations (DEP10 and DEP50) for $2 \mathrm{~h}$. Along with DEPs exposure, an RT-PCR assay was performed to verify the autophagy and antioxidation markers using autophagy and Nrf2 system controls. The following substances were used as controls: 1) EBSS to induce starvation in cells; 2) sulforaphane at a $10 \mu \mathrm{M}$ concentration for $2 \mathrm{~h}$ to activate the Nrf2 system; and 3) bafilomycin at a $10 \mathrm{nM}$ concentration for $4 \mathrm{~h}$ to inhibit autophagic flux. We analysed the following genes: 1) LC3B, p62 and Atg5 in the autophagy pathway and 2) Nrf2, NQO1 and HO-1 in the antioxidant pathway. 


\begin{tabular}{|c|c|c|c|}
\hline HPA & Recovery (\%) & \multicolumn{2}{|c|}{ Result (ng/g) } \\
\hline Fluorene & 74 & \multicolumn{2}{|l|}{11} \\
\hline Phenanthrene & 96 & \multicolumn{2}{|l|}{47} \\
\hline Anthracene & 53 & \multicolumn{2}{|l|}{7} \\
\hline Fluoranthene & 81 & \multicolumn{2}{|l|}{35} \\
\hline Pyrene & 74 & \multicolumn{2}{|l|}{32} \\
\hline Benzo(a)anthracene & 65 & \multicolumn{2}{|l|}{8} \\
\hline Criseno & 66 & \multicolumn{2}{|l|}{15} \\
\hline $\mathrm{BbF}$ & 73 & \multicolumn{2}{|l|}{32} \\
\hline $\mathrm{BkF}$ & 70 & \multicolumn{2}{|l|}{11} \\
\hline $\mathrm{BeP}$ & 74 & \multicolumn{2}{|l|}{25} \\
\hline $\mathrm{BaP}$ & 69 & \multicolumn{2}{|l|}{22} \\
\hline $\mathrm{InP}$ & 85 & \multicolumn{2}{|l|}{6} \\
\hline DBA & 93 & \multicolumn{2}{|l|}{13} \\
\hline BPer & 88 & \multicolumn{2}{|l|}{53} \\
\hline Cor & 92 & \multicolumn{2}{|l|}{170} \\
\hline Elemental Carbon (EC) & \multicolumn{3}{|c|}{ Organic Carbon (OC) } \\
\hline \multirow{3}{*}{$69,30 \%$} & \multicolumn{3}{|l|}{30,7} \\
\hline & Oca & $\mathrm{OCb}$ & PC \\
\hline & 0,3 & 3,9 & 26,6 \\
\hline
\end{tabular}

Table 2. Result of organic fraction of DEP by gas chromatography. The acronyms correspond respectively to the compounds: Benzo (b) fluoranthene (BbF), Benzo (k) fluoranthene (BkF), Benzo (e) pyrene (BeP), Benzo, 3-cd) pyrene (Ind), Dibenzo (a, h) anthracene (DBA) and Benzo (ghi) perylene (BPe).

A

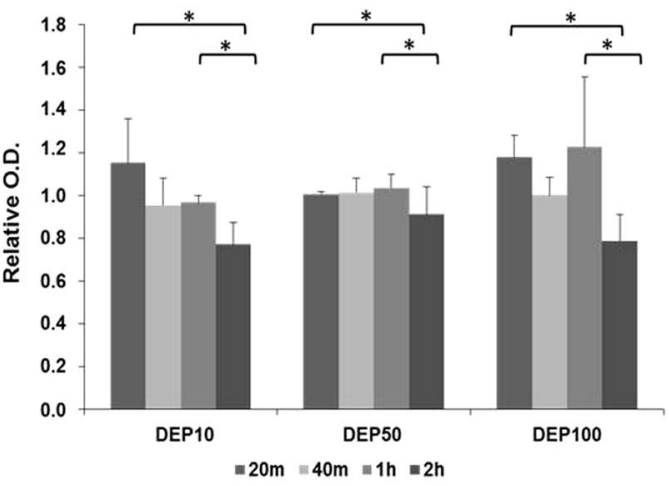

B

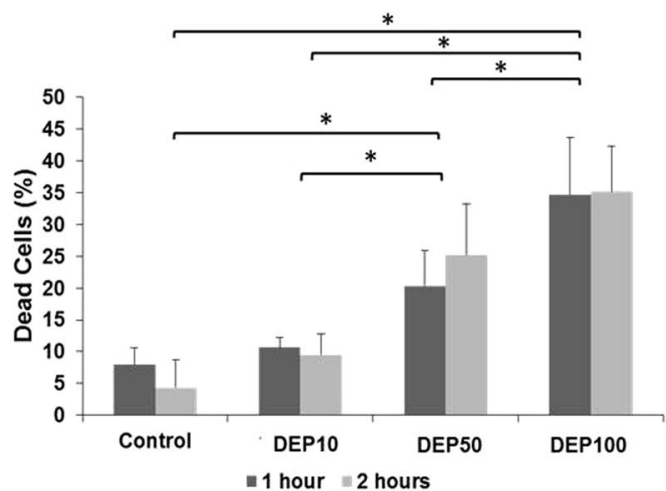

Figure 1. Cytotoxicity Assays: (A) Results from the analysis of formazan absorbance produced by cells exposed only to LHC-9 culture medium (control), DEP at $10 \mu \mathrm{g} / \mathrm{mL}$, DEP at $50 \mu \mathrm{g} / \mathrm{mL}$, and DEP at $100 \mu \mathrm{g} / \mathrm{mL}$. A significant difference was found for exposure times $(\mathrm{p}=0.015)$. Results from the Holm-Sidak test showed a difference between the times of $20 \mathrm{~min}$ and $2 \mathrm{~h}(\mathrm{p}=0.009)$ and between the times of $1 \mathrm{~h}$ and $2 \mathrm{~h}(\mathrm{p}=0.01)$ for the groups exposed to the DEP. (B) Results from the analysis of the percentage of dead cells that had been exposed only to LHC-9 culture medium (control), $10 \mu \mathrm{g} / \mathrm{mL} \mathrm{DEP} \mathrm{or} 50 \mu \mathrm{g} / \mathrm{mL}$ DEP. A significant difference was found for concentrations $(\mathrm{p}=0.004)$. The Holm-Sidak method showed a difference between groups: $100 \mu \mathrm{g} / \mathrm{mL}$ vs. the control $(\mathrm{p}=0.009) ; 100 \mu \mathrm{g} / \mathrm{mL}$ vs. $10 \mu \mathrm{g} / \mathrm{mL}(\mathrm{p}=0.010) ; 100 \mu \mathrm{g} / \mathrm{mL}$ vs. $50 \mu \mathrm{g} / \mathrm{ml}(\mathrm{p}=0.025) ; 50 \mu \mathrm{g} / \mathrm{mL}$ vs. the control ( $\mathrm{p}=0.007)$; and $50 \mu \mathrm{g} / \mathrm{mL}$ vs. $10 \mu \mathrm{g} / \mathrm{ml}(\mathrm{p}=0.015)$.

The results showed that DEP50 treatment lead to increased gene expression for both Nrf2-system and autophagy markers (Fig. 2A-E), mainly when compared with autophagy controls EBSS and bafilomycin. DEP10 treatment increased Nrf2, HO-1 and p62 levels, mainly when compared with control and bafilomycin treatments (Fig. 2A,C,D), indicating that both treatments are able to interfere in both pathways. Interestingly, Nrf2-system induction by sulforaphane increased the expression of the autophagy markers p62 and LC3B (Fig. 2D,E), mainly when compared to control, whereas autophagy impairment by bafilomycin negatively interfered with the expression of Nrf2-regulated proteins: Nrf2, NQO1 and HO-1 (Fig. 2A-C), mainly when compared to DEP50 treatment. These results indicate that were able to interfere in both pathways (Fig. 2A-E).

Nrf2 positively regulates autophagy markers in DEP exposure. Silencing RNA (siRNA) specific to Nrf2 was used to reduce its activity in the BEAS-2B cells. After $48 \mathrm{~h}$ of culture for transfection, the cells were 
A

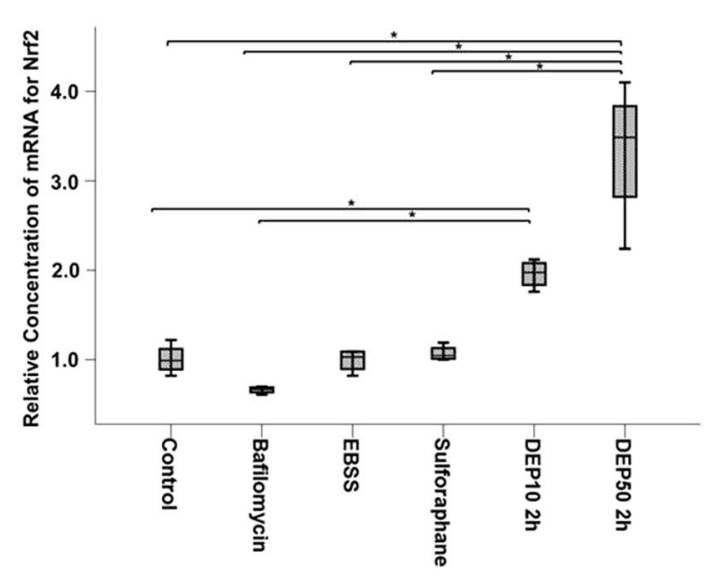

C

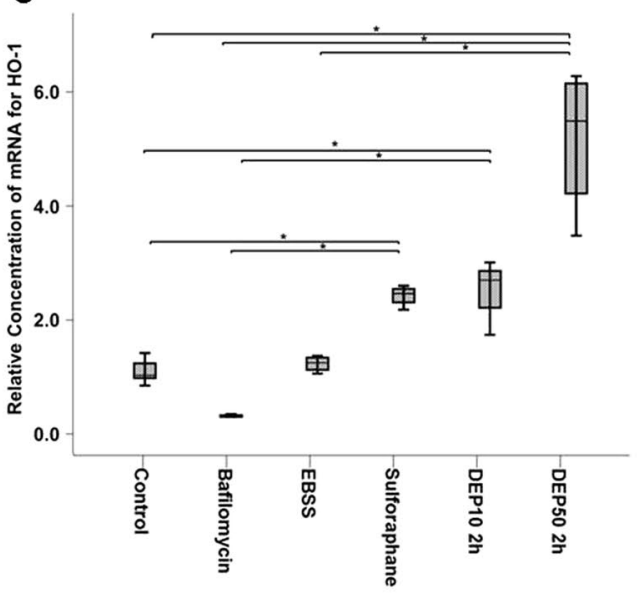

E

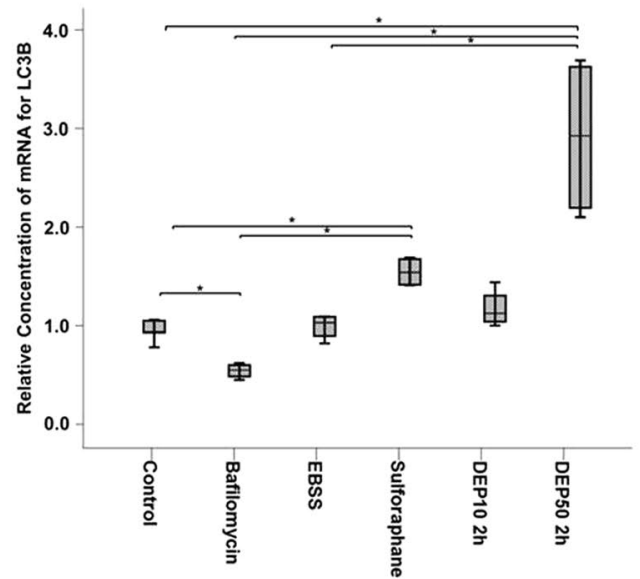

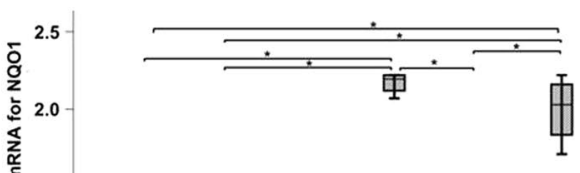

D

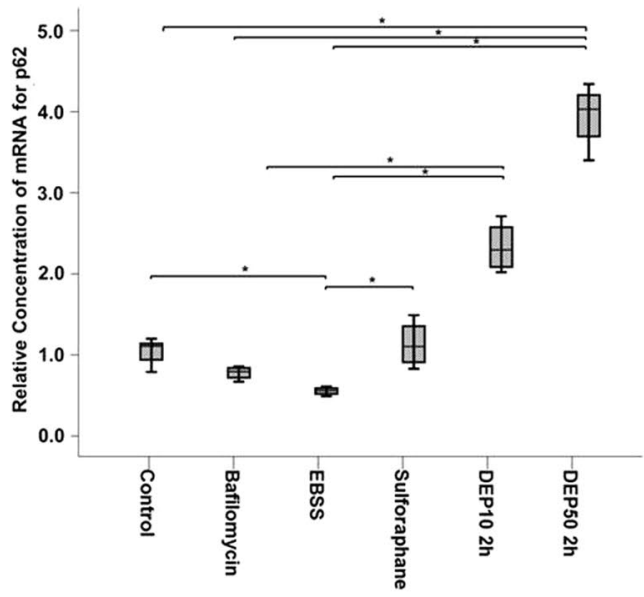

Figure 2. Results of gene expression analysis (RT-PCR) for the autophagy and Nrf2-system markers after exposure to 10 and $50 \mu \mathrm{g} / \mathrm{mL}$ DEP for $2 \mathrm{~h}$, EBSS for $40 \mathrm{~min}, 10 \mathrm{nM}$ bafilomycin for $4 \mathrm{~h}$ and $10 \mu \mathrm{M}$ sulforaphane for $24 \mathrm{~h}$. The quantities were calculated by the $2^{-\Delta \Delta \mathrm{CT}}$ method. (A) Nrf2: there was a significant difference $(\mathrm{p}<0.001)$, and the pairwise test showed a difference between treatments: DEP50 vs control, $(\mathrm{p}=0.003)$, bafilomycin $(p<0.001)$, EBSS $(p=0.011)$ and sulforaphane $(p=0.042)$; DEP10 vs control $(p=0.03)$ and bafilomycin $(\mathrm{p}<0.001)$. (B) NQO1: there was a significant difference $(\mathrm{p}<0.001)$, and the pairwise test showed a difference between DEP50 vs control $(\mathrm{p}=0.015)$, bafilomycin $(\mathrm{p}<0.001)$ and DEP10 $(\mathrm{p}=0.017)$; sulforaphane vs control $(\mathrm{p}=0.005)$, bafilomycin $(\mathrm{p}<0.001)$ and DEP10 $(\mathrm{p}=0.006)$; bafilomycin vs EBSS $(\mathrm{p}=0.010)$. (C) HO-1: there was a significant difference $(\mathrm{p}<0.001)$, and the pairwise test showed a difference between DEP50 vs control $(p=0.001)$, bafilomycin $(p<0.001)$ and EBSS $(p=0.017)$; DEP10 vs control $(\mathrm{p}=0.015)$ and bafilomycin $(\mathrm{p}=0.001)$; sulforaphane vs control $(\mathrm{p}=0.41)$ and bafilomycin $(\mathrm{p}=0.003) ;(\mathrm{D})$ p62: there was a significant difference $(\mathrm{p}<0.001)$, and the pairwise test showed a difference between: DEP50 
vs control $(\mathrm{p}=0.008)$, bafilomycin $(\mathrm{p}=0.001)$ and EBSS $(\mathrm{p}<0.001)$; DEP10 vs bafilomycin $(\mathrm{p}=0.009)$ and EBSS $(p<0.001)$; EBSS vs control $(p=0.026)$ and sulforaphane $(p=0.022)$. (E) LC3B: there was a significant difference $(p<0.001)$, and the pairwise test showed a difference between DEP50 vs control $(p=0.001)$, bafilomycin $(p<0.001)$ and EBSS $(p=0.18)$; bafilomycin vs DEP10 $(p=0.13)$ and sulforaphane $(p=0.001)$; control vs sulforaphane $(\mathrm{p}=0.020)$.

exposed to DEP at concentrations of 10 and $50 \mu \mathrm{g} / \mathrm{mL}$ for $1 \mathrm{~h}$ and $2 \mathrm{~h}$. The results showed that siRNA treatment significantly reduced the amount of $\mathrm{p} 62(\mathrm{p}=0.001)$ (Fig. 3D) and LC3B $(\mathrm{p}<0.001)$ (Fig. 3C). The non-transfected BEAS-2B cells exposed to DEP at a concentration of $10 \mu \mathrm{g} / \mathrm{mL}$ for $2 \mathrm{~h}$ had increased Atg $5 \mathrm{mRNA}$ levels $(\mathrm{p}=0.007)$ (Fig. 3E), indicating that DEP induced Atg 5 when Nrf2 was active in the cells. However, when Nrf2 was reduced through siRNA, there was a significant Atg 5 decrease in the BEAS-2B cells transfected with siRNA compared with that in the BEAS-2B cells exposed to siDEP50 for $2 \mathrm{~h}(\mathrm{p}=0.024)$, thereby confirming that the Atg 5 response is dependent on $\mathrm{Nrf} 2$.

siRNA treatment reduced the protein amount. To determine the proportion of each protein expressed under these conditions, Western blotting was performed with Nrf2, LC3B and p62 (Fig. 4). When compared to the levels of the BEAS-2B NTC cell groups, an evident decrease in these proteins was observed for all the siRNA-transfected BEAS-2B cell groups. For the BEAS-2B NTC cells, the results from the analysis of the Western blot bands showed an increase in Nrf2 after $2 \mathrm{~h}$ of exposure to DEP50 $(\mathrm{R}=1.43)$ (Fig. $4 \mathrm{C})$ and an increase in p62 in the BEAS-2B cells exposed to DEP10 $(\mathrm{R}=1.3$ for $1 \mathrm{~h}$ and $\mathrm{R}=2.1$ for $2 \mathrm{~h}$ ) (Fig. 4E). The amount of LC3II the functional form of LC3B - was increased in the DEP10 $1 \mathrm{~h}$ group $(\mathrm{R}=1.46)$ and DEP50 $1 \mathrm{~h}$ group $(\mathrm{R}=1.3)$ (Fig. 4F). LC3II was decreased in the siRNA-transfected BEAS-2B cells exposed to DEP10 for $1 \mathrm{~h}$, DEP10 for $2 \mathrm{~h}$ and DEP50 for $2 \mathrm{~h}$ to a greater extent than it was in the cells treated with siRNA alone (Fig. 4F).

Autophagosomes were reduced in the siRNA-transfected cells. An immunofluorescence assay was performed with the BEAS-2B cells to verify autophagosome formation and Nrf2 protein expression (Fig. 5). The yellow appearance after the images were merged (Merge) indicates the overlap between the green and red markers; i.e., both proteins were present in the cell: LC3B (green) and Nrf2 (red). As shown in Fig. 5A, autophagosomes are identified as bright green dots in both the LC3B and the Merge columns. The DEP10 $2 \mathrm{~h}$ and DEP50 $2 \mathrm{~h}$ groups had a higher number of green spots compared to that in the other groups, indicating that the autophagy was more intense in these groups. In the merged image of the DEP50 $2 \mathrm{~h}$ group, the orange tone indicates the high intensity of the red spots (Nrf2). Figure $5 \mathrm{~B}$ shows the BEAS-2B cells transfected with siRNA. The red staining is less intense because of Nrf2 suppression. LC3B is represented by positive green dots, and although less intense, they indicate that autophagy remained active when the cells were transfected with siRNA; however, autophagy remained much less active compared that in the non-transfected BEAS-2B cells.

\section{Discussion}

In the present study, BEAS-2B cells were exposed to DEP at different times and concentrations to assess autophagy and antioxidant responses. The results indicate that DEP decrease cell viability and elicit the response of both biochemical pathways. The results of this study showed that the DEP concentrations of 10 and $50 \mu \mathrm{g} / \mathrm{mL}$ for $2 \mathrm{~h}$ of exposure can activate both the antioxidant pathway - increasing the expression of Nrf2, HO- 1 and NQO 1 - and the autophagy pathway — increasing p62 and LC3B expression. However, there were different responses between the two concentrations, which may be explained by particles behaviour in liquid solutions, since according to Seriani et al. ${ }^{29}$ at higher concentrations DEP tends to form large clusters while lower concentrations can penetrate epithelial cells more easily and fast, which may cause a different reaction in epithelium. In addition, siRNA treatment showed that autophagy is downregulated when the Nrf2 transcription factor showed low activity, indicating a positive relationship between the two mechanisms in maintaining cell survival in BEAS-2B cells exposed to DEP.

Nrf2 is a transcription factor that regulates a series of proteins with promoter regions that have an ARE motif, including some genes related to autophagy, such as $\mathrm{p} 62$ and Atg $5^{25}$. The results of the present study indicate that Nrf2 activation positively regulates DEP-induced autophagy at the transcriptional level, as indicated by the considerable decrease in autophagy markers when Nrf2 was inhibited by siRNA, even during DEP exposure. Nrf2 suppression caused a significant decrease in the relative amounts of p62 and LC3B mRNA and decreased the relative protein levels of p62 and LC3II (Fig. 4). On the other hand, in the controls, sulforaphane-induced Nrf2 caused increased expression of Atg5, LC3B and p62. Taken together, the results showing the response of these autophagy markers - decreasing when Nrf2 is inhibited or increasing when Nrf2 is expressed - suggest that this transcription factor positively controls the transcription of these genes.

The immunofluorescence analysis results showed that the siRNA treatment reduced the frequency of green spots, as observed when the groups shown in Fig. 5A were compared to those shown in Fig. 5B. The BEAS-2B cells exposed to DEP for $2 \mathrm{~h}$ had yellow spots in Merge [a result of the overlapping LC3B (green) with Nrf2 (red)], greater intensity of the red dots representing Nrf2 and the green spots representing LC3B, attesting to the fact that DEP can induce both autophagy and the antioxidant pathway at the same time. The siRNA-transfected BEAS-2B cell groups showed a less intense yellow in the merged image than did the BEAS-2B cells not transfected with siRNA. The autophagy markers that were observed in the siRNA-transfected BEAS-2B cell groups can be considered long-lasting proteins that had already been produced in the cell prior to the siRNA transfection and may have been recycled by the autophagy mechanism itself, as indicated by the low levels of LC3B, Atg 5 and p62 mRNA, which do not reflect de novo synthesis of these proteins. 
A

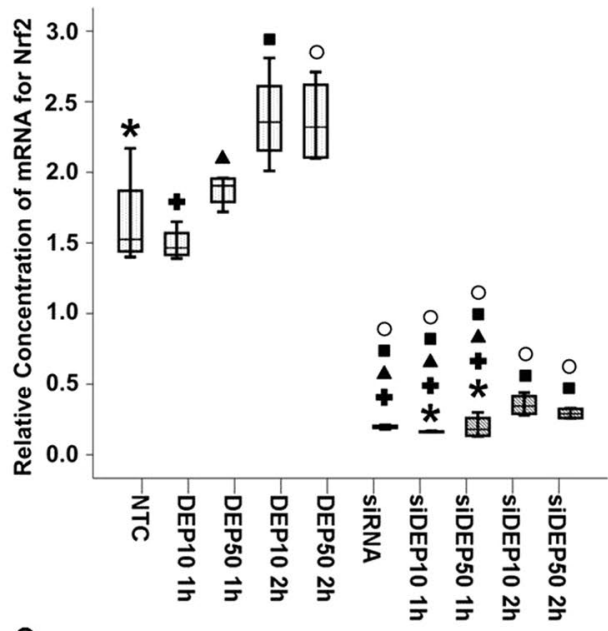

C

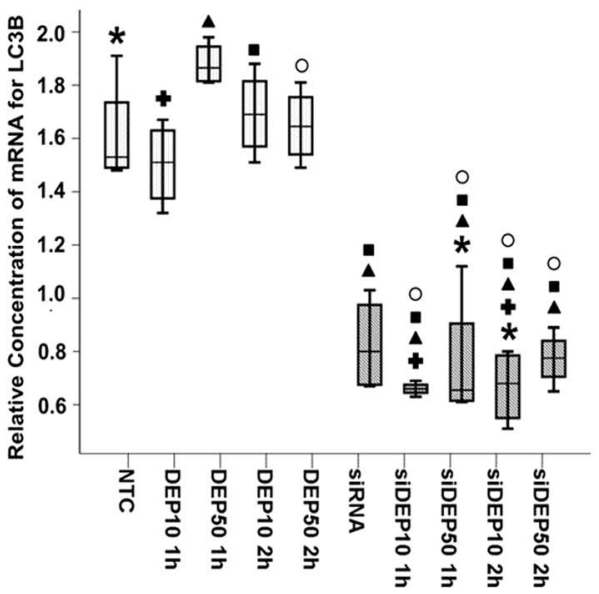

E

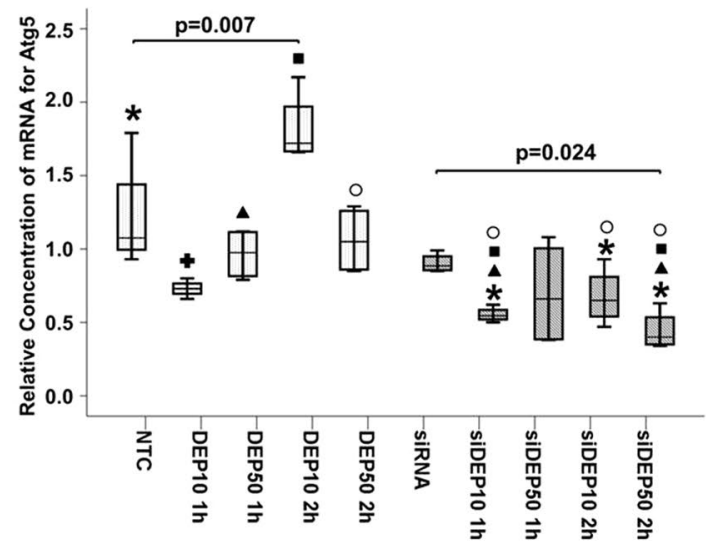

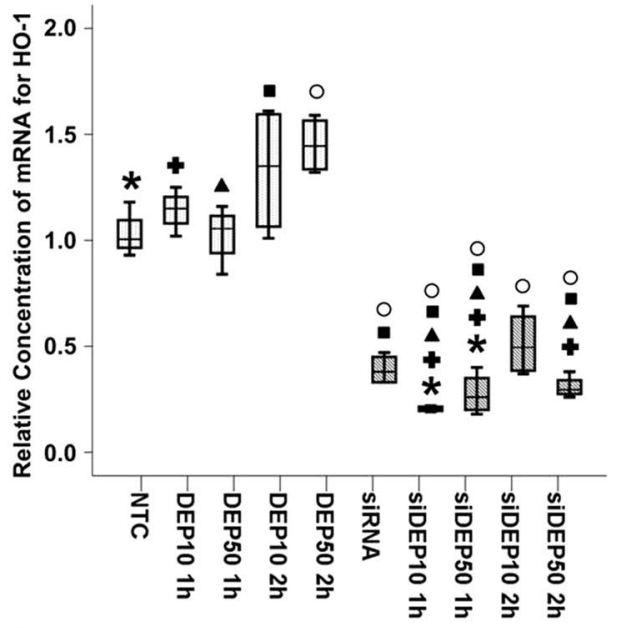

D

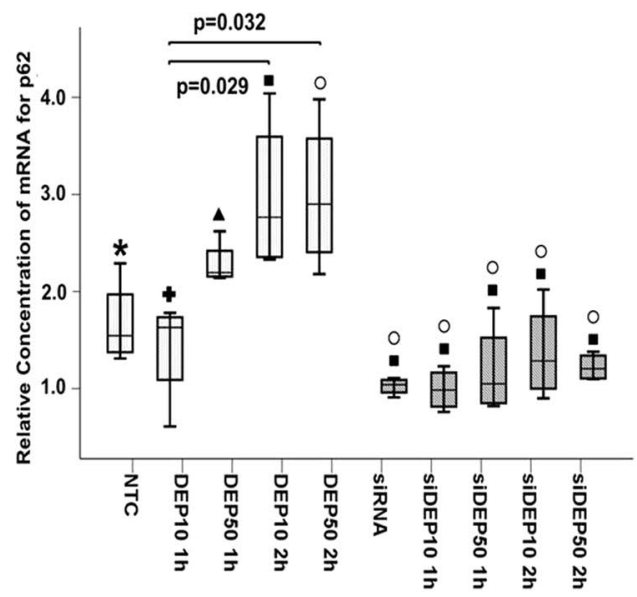

Figure 3. Expression of autophagy and antioxidant markers in Nrf2-specific siRNA-transfected BEAS-2B cells exposed to DEP at concentrations of $10 \mu \mathrm{g} / \mathrm{mL}$ and $50 \mu \mathrm{g} / \mathrm{mL}$ for $1 \mathrm{~h}$ and $2 \mathrm{~h}$. The relative concentration of mRNA markers was determined by the $2^{-\Delta \Delta C T}$ method. The results of the Kruskal-Wallis test showed a significant difference between the cells transfected with siRNA and non-transfected cells for the following genes: (A) Nrf2 (p < 0.001); (B) HO-1 (p<0.001), (C) LC3B (p<0.001), (D) p62 (p=0.001), and (E) Atg5 (p=0.001). The pairwise multiple comparison test showed the differences between paired groups. The symbols “*”, “+”, “ $\mathbf{\Delta}$ ", "匹" and " $\circ$ " represent the NTC, DEP10 1 h, DEP50 1 h, DEP10 2 h, and DEP50 2 h groups, respectively. Above the siRNA and siDEP group box plots, the list of symbols indicates significant results compared to the results of the NTC and DEP groups. The values of $\mathrm{p}$ for the pairs are described in Tables 5-9 in the online resource. 
A

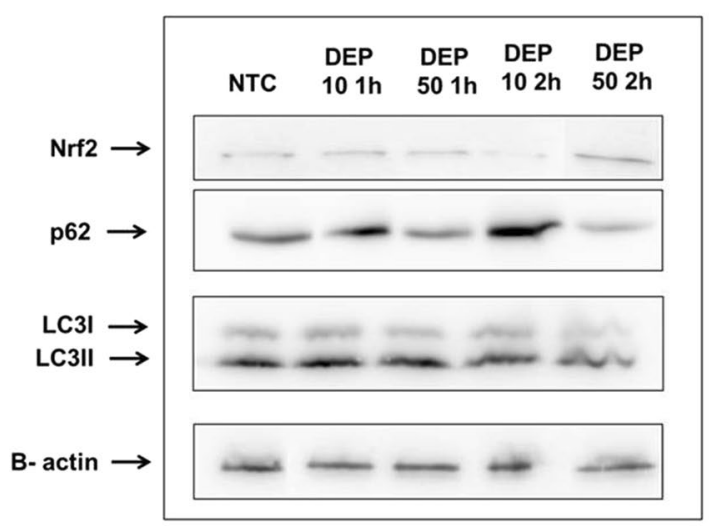

C

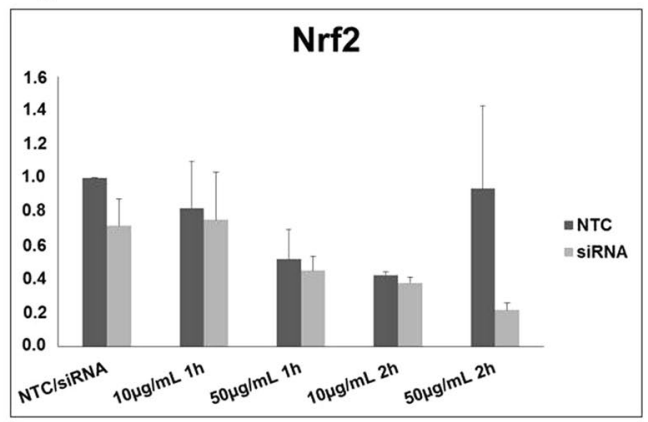

D

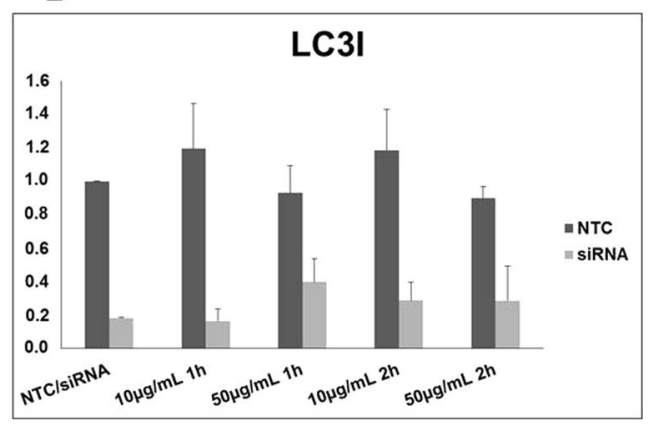

B

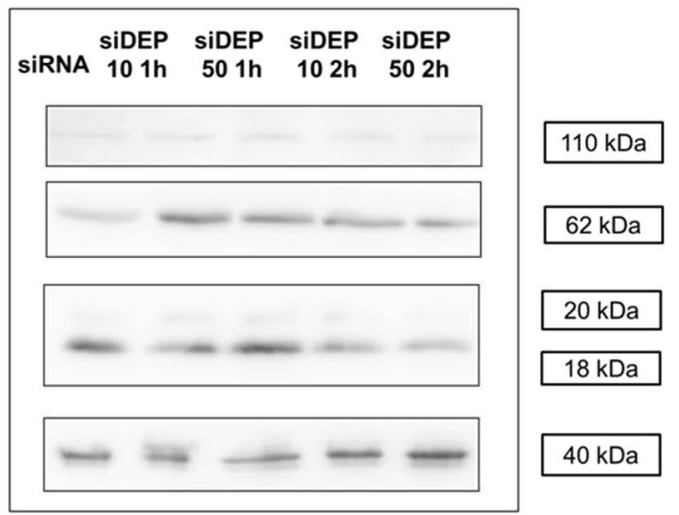

$\mathbf{E}$

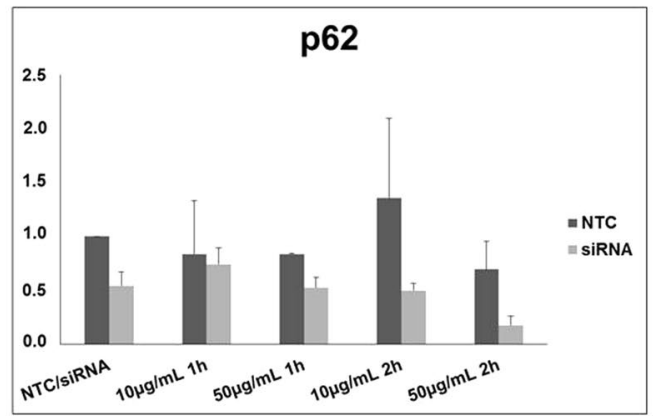

$\mathbf{F}$

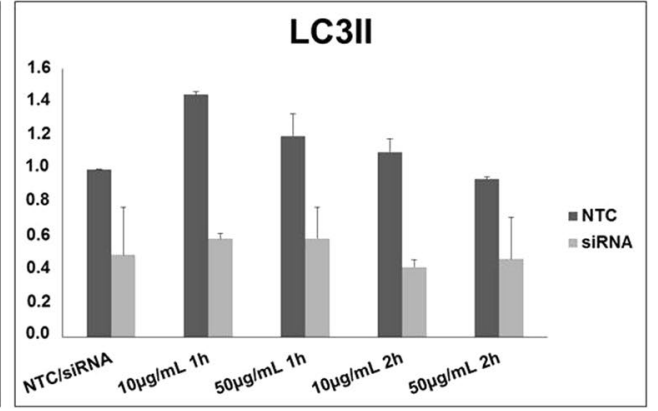

Figure 4. Proteins in the PVDF membranes as revealed by chemiluminescence. Samples were derived from the same experiment, and both gels were processed in parallel. The autophagy markers p62 and LC3I and II were analysed along with the expression of Nrf2. (A) Groups of cells transfected with the negative control and exposed to DEP at concentrations of 10 and $50 \mu \mathrm{g} / \mathrm{mL}$ for $1 \mathrm{~h}$ and $2 \mathrm{~h}$. All proteins in these groups were in the same membrane. (B) Groups of cells transfected with siRNA for Nrf2 and exposed to DEP at concentrations of 10 and $50 \mu \mathrm{g} / \mathrm{mL}$ for $1 \mathrm{~h}$ and $2 \mathrm{~h}$. All proteins shown are in the same membrane. The ratio of protein expression was determined by normalizing the expression of each protein of interest to that of $\beta$-actin and the normalized value ratio to that of the control value (NTC). Thus, $\mathrm{R}$ (ratio) $>1$ is considered to indicate increased protein level and $\mathrm{R}<1$ indicates decreased protein level. All $\mathrm{R}$ values are shown in tabular form in the online resources (Table 10).

Autophagy induction has been linked to air pollution exposure. Lai et al..$^{30}$ exposed A549 cells to DEP, urban dust and black carbon and found a significant increase in autophagy as indicated by the conversion of LC3I to LC3II. Long et al. ${ }^{14}$ demonstrated that exposure of bronchial cells to $2.5 \mu \mathrm{m}$ PM induced autophagy by overexpressing Atg 5 and beclin-1, increasing the ratio of LC3I to LC3II proteins and increasing autophagosome formation. Bai et al. ${ }^{12}$ showed that $\mathrm{PM}_{1}(1 \mu \mathrm{m})$ at a concentration of $100 \mu \mathrm{g} / \mathrm{mL}$ induces autophagy and intracellular oxidative stress in type II alveolar epithelial cells in a dose-dependent manner. The authors also pre-treated the cells with antioxidants and chelators to show that the oxidative stress promoted by the particles was generated by the metals present in the PM composition ( $\mathrm{Fe}, \mathrm{Cu}$ and $\mathrm{Mn}$ ). These pre-treatments also reduced the induction of autophagy in these cells compared to that in the cells treated with $\mathrm{PM}_{1}$ only. However, few studies have reported the participation of Nrf2 in the regulation of autophagy after PM or DEP exposure.

The relationship between the autophagy and antioxidant pathways mediated by Keap1-Nrf2 has been addressed in several studies using different substances. Wang et al. ${ }^{31}$ used cadmium-induced malignant 
A
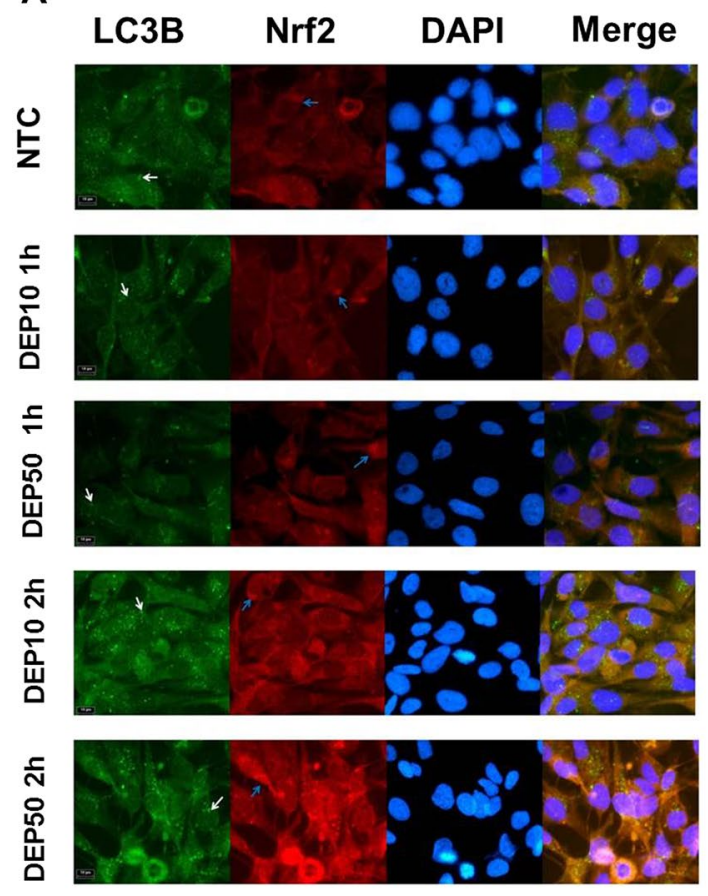

B


Figure 5. Results of the immunofluorescence method: (A) cells transfected with the negative control and (B) cells transfected with siRNA groups. The blank arrows in the LC3B and Merge columns indicate more intense green spots corresponding to the autophagosomes. The blue arrows in the Nrf2 column indicate some positive markers, for which the red fluorescence is more intense. In the last column, Merge indicates the overlap of the green (LC3B), red (Nrf2) and DAPI images. The yellowish colour in the Merge image indicates the overlapping of the red and green colours, whereas the more intense green spots correspond to autophagosomes. Images were acquired with an Olympus BX51 microscope at $40 \times$ and $2 \times$ magnification using Image Pro Plus software. Merged images were generated using ImageJ software.

transformation of BEAS-2B cells and found deficient autophagy levels, accumulation of p62 and constitutive activation of Nrf2 in these cells. However, sulforaphane treatment was able to restore autophagic flux and decrease $\mathrm{Nrf} 2$ expression in the transformed cells. In normal BEAS-2B cells, sulforaphane promoted Nrf2 activation, increased autophagy levels and decreased ROS levels, indicating that sulforaphane (and, as a consequence, Nrf2 activation) plays a dual role in regulating autophagy.

Son et al. ${ }^{32}$ used nickel-transformed BEAS-2B cells and showed increased LC3II levels and overexpression of Stat3, a protein with a promoter region that has an ARE binding site. When Stat3 levels were suppressed, a reduction in LC3II level was found, while Nrf2 suppression resulted in depletion of Stat3, indicating that Nrf2 exerts an influence on the sensitivity of autophagy. Shah et al. ${ }^{33}$ demonstrated that arsenic induces p62 expression in vivo and in vitro. Keratinocytes were transfected with siRNA specific to Nrf2, resulting in the suppression of p62 expression, even when the keratinocytes were exposed to arsenic. The authors concluded that Nrf2 is the transcription factor critical for p62 expression. To elucidate the positive relationship between p62 and Nrf2, the authors treated the cells with siRNA for p62, having found decreased expression of HO-1, NQO1 and GCLC proteins, which each had a promoter region activated by Nrf2, indicating that Nrf2 depends on $\mathrm{p} 62$ to be activated and vice versa.

However, in some studies, Nrf2 was associated with an inhibitor of autophagy. Lau et al ${ }^{34}$ demonstrated that arsenic exposure in BEAS-2B cells activated Nrf2, disrupting autophagic flux and the accumulation of p62 and LC3B, resulting in a connection between Keap1 and p62. Additionally, when cells were treated with sulforaphane, a Nrf2 activation promoter, the autophagosome levels decreased. Zhu et al. ${ }^{35}$ demonstrated that exposure of BEAS-2B cells to cigarette smoke extract (CSE) increased the expression of LC3I and LC3II, p62 and NQO1. However, increased Nrf2 expression via inhibition of Keap1 resulted in decreased expression of LC3B, whereas siRNA specific to Nrf2 restored the levels of LC3I and II in the cells exposed to CSE, suggesting that Nrf2 activation can negatively regulate autophagy.

The divergence found in these studies indicates that the influence of Nrf2 on the autophagy pathway has not been fully comprehended. Antioxidant defence and autophagy are both involved in maintaining homeostasis and cell survival but may interact differently depending on the level of stress, suggesting that Nrf2 may be an important sensor of cell survival/cell death ${ }^{36}$. The results of the MTT and Trypan blue assays showed that the DEP caused a significant decrease in cell viability, indicating their toxicity. Several studies have pointed out that the cytotoxicity induced by exposure to DEP can lead to cell death events such as apoptosis ${ }^{37}$ and necrosis ${ }^{38}$. Li et al. ${ }^{39}$ compared BEAS-2B cells and macrophages after exposure to DEP and demonstrated that BEAS-2B cells were more susceptible to the effect of the pollutant, causing a significant increase in necrotic cells. Seriani et al ${ }^{40}$ 


\begin{tabular}{|l|l|}
\hline Groups & Description \\
\hline siRNA & BEAS-2B transfected with siRNA to Nrf2 \\
\hline siDEP10 $1 \mathrm{~h}$ & BEAS-2B transfected and exposed to DEP10 $\mu \mathrm{g} / \mathrm{mL}$ for $1 \mathrm{~h}$ \\
\hline siDEP50 $1 \mathrm{~h}$ & BEAS-2B transfected and exposed to DEP50 $\mu \mathrm{g} / \mathrm{mL}$ for $1 \mathrm{~h}$ \\
\hline siDEP10 $2 \mathrm{~h}$ & BEAS-2B transfected and exposed to DEP10 $\mu \mathrm{g} / \mathrm{mL}$ for $2 \mathrm{hs}$ \\
\hline siDEP50 $2 \mathrm{~h}$ & BEAS-2B transfected and exposed to DEP50 $\mu \mathrm{g} / \mathrm{mL}$ for $2 \mathrm{hs}$ \\
\hline NTC - Negative Control & BEAS-2B transfected with negative control \\
\hline DEP10 $1 \mathrm{~h}$ & NTC BEAS-2B exposed to DEP $10 \mu \mathrm{g} / \mathrm{mL}$ for $1 \mathrm{~h}$ \\
\hline DEP50 $1 \mathrm{~h}$ & NTC BEAS-2B exposed to DEP $50 \mu \mathrm{g} / \mathrm{mL}$ for $1 \mathrm{~h}$ \\
\hline DEP10 $2 \mathrm{~h}$ & NTC BEAS-2B exposed to DEP $10 \mu \mathrm{g} / \mathrm{mL}$ for $2 \mathrm{hs}$ \\
\hline DEP50 $2 \mathrm{~h}$ & NTC BEAS-2B exposed to DEP $50 \mu \mathrm{g} / \mathrm{mL}$ for $2 \mathrm{hs}$ \\
\hline
\end{tabular}

Table 3. Study Groups for BEAS-2B transfected.

\begin{tabular}{|l|l|l|}
\hline Gene & Primer Forward & Primer Reverse \\
\hline Nrf2 & GCTATGGAGACACACTACTTGG & CCAGGACTTACAGGCAATTCT \\
\hline Keap1 & CGTCCTGCACAACTGTATCT & GTGTCTGTATCTGGGTCGTAAC \\
\hline NQO1 & GGAAGAAACGCCTGGAGAATA & CAGGGAAGCCTGGAAAGATAC \\
\hline HO-1 & GGTCCTTACACTCAGCTTTCT & CATAGGCTCCTTCCTCCTTTC \\
\hline p62 & GGAACAGATGGAGTCGGATAAC & CTGGAAGAAGGCAGAGAAACT \\
\hline LCB3 & AGAGCAGCATCCAACCAAAAT & TGAGCTGTAAGCGCCTTCTAA \\
\hline ATG5 & GCAACTCTGGATGGGATTGC & AGGTCTTTCAGTCGTTGTCTGAT \\
\hline RPL13A & AAGGTGGTGGTCGTACGCTGTG & CGGGAAGGGTTGGTGTTCATCC \\
\hline
\end{tabular}

Table 4. Primers sequences.

demonstrated that, at the transcriptional level, BEAS-2B cells exposed to DEP at $15 \mu \mathrm{g} / \mathrm{mL}$ had significantly increased expression of the apoptotic protein caspase- 3 and decreased expression of antioxidant enzymes, such as superoxide dismutase 1 and 2 (SOD1 and SOD2). Autophagy can be related as a cell death process, but is a different mechanism from apoptosis, also known as programmed cell death, characterized by several characteristic morphological changes in cell structure and with various enzyme-dependent biochemical processes ${ }^{41}$. However, in this study, cells had no apoptosis markers (data not shown) and had more than $70 \%$ of survival rate after DEP50 treatment and more than 90\% after DEP10 treatment (Fig. 1), indicating that cells were on the threshold of a response to damage but were not on the threshold of death.

Therefore, the positive or negative regulation of autophagy and/or the antioxidant pathway can be attributed to the nature of the stimulus - and in the case of this study, to DEP, in particular. To determine whether the composition of the collected material was similar to that expected, the PAHs and elements were characterized (Tables 3 and 4). Although the characterization of DEP is the subject of studies seeking to understand how exposure causes adverse health effects ${ }^{42}$, no patterns of quality or quantity have been determined for the regulation of these specific elements in the air, making it difficult to determine the threshold of the amount of the element in cellular damage. Nevertheless, this is the first study to show a dependent relationship between autophagy and Nrf2 pathways after DEP exposure, indicating that the Nrf2 oxidative stress response positively regulates autophagy at the transcriptional level.

In conclusion, this study showed that both the antioxidant defence promoted by Nrf2 and the autophagy mechanism acted together in the BEAS-2B cells exposed to diesel exhaust particulate matter through an increase in the expression of Nrf2, HO-1 and NQO1 and in the autophagy pathway proteins p62 and LC3B. However, the data available from the literature about how these mechanisms are related are conflicting. Our results indicated that the type of substance utilized (DEP) and the level of stress induced in the cell line used were determinants of the positive relationship between these pathways (Fig. 6). To test this hypothesis, further experiments are needed to determine whether any fraction or any specific component of the DEP is critical for the positive relationship between Nrf2 and autophagy presented here.

\section{Materials and Methods}

This research was approved by the Ethical Committee of the School of Medicine of São Paulo University (number 119/15).

Cell culture. A culture of BEAS-2B human bronchial epithelial cells, from an immortalized line (purchased from Sigma-Aldrich, Steinheim Germany, derived from normal bronchial epithelium obtained from autopsy of a non-cancerous individual) was prepared in flasks or plates coated with Matrigel (a substance that mimics the extracellular matrix) in the presence of LHC-9 growth medium supplemented with $10 \%$ foetal bovine serum, $0.1 \% 2 \mathrm{mM}$ L-glutamine, $1 \%$ antibiotic, $0.1 \% 1 \mathrm{mM}$ pyruvate, and $0.1 \%$ non-essential $1 \mathrm{mM}$ amino acids. The bottles and plates were kept in a humidified $\mathrm{CO}_{2}$ incubator at $37^{\circ} \mathrm{C}$. 
A

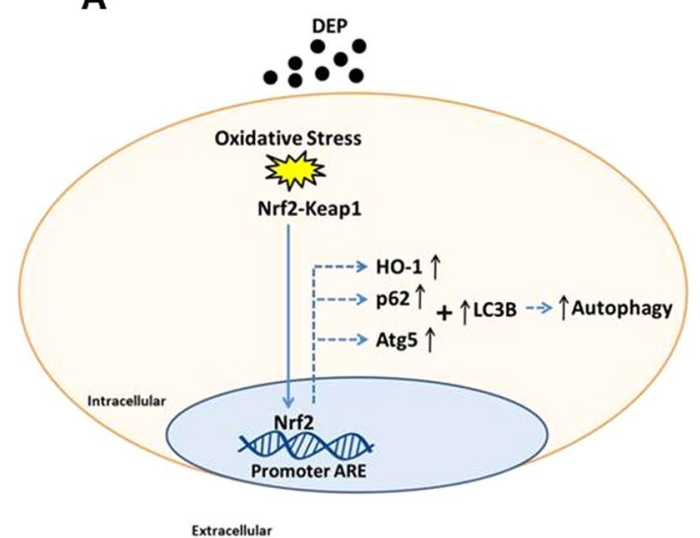

B

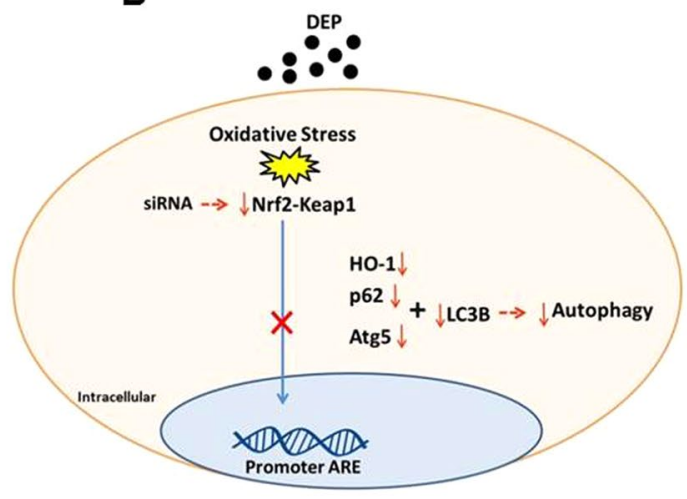

Figure 6. Summary of study completion. (A) DEP causes oxidative stress in cells, activating the Nrf2-system, which promotes antioxidant enzymes expression and positively regulates autophagy response. (B) under a decrease in Nrf2 expression, there is a drastic decrease in expression of antioxidant enzymes and autophagy markers.

Chemicals and treatment. Cells were exposed to bafilomycin (Sigma Aldrich) at $10 \mathrm{nM}$ for $4 \mathrm{~h}$ as a negative control of autophagic pathways ${ }^{43}$. Exposure to EBSS (Earle's balanced salt solution, Gibco) for 40 min was used to promote cell starvation. Sulforaphane (Sigma Aldrich) was used at $10 \mu \mathrm{M}$ for $24 \mathrm{~h}$ as a positive control of the Nrf2 system ${ }^{44}$. All supplements were removed from the LHC-9 medium $2 \mathrm{~h}$ before each experiment.

Diesel exhaust particulate and treatment. The DEP used in this study were collected from a diesel engine using a particulate retainer, a bimetallic filter that creates a field capable of holding the particulate matter emitted from exhaust. The vehicle chosen was a 2004 model Volkswagen bus with a 6-cylinder MWM $\mathrm{x}-10$ engine. The bus is the property of a private company and circulates in the neighbourhood of Campo Belo, in Sao Paulo City, Brazil. The bus runs approximately 100 to $150 \mathrm{~km} /$ day, and the particle retainer was linked to the exhaust for 1 week. DEP were collected in September/October of 2015. Next, the DEP were removed from the particle retainer and weighed. For BEAS-2B cell exposure, the DEP were diluted 1:1 $(1 \mathrm{mg} / \mathrm{mL})$ in phosphate-saline solution (PBS) with $0.1 \%$ ethanol. The DEP were diluted in culture medium at concentrations of 10,50 , and $100 \mu \mathrm{g} / \mathrm{mL}$.

Diesel exhaust characterization. As recommended by Laks et al. ${ }^{45}$, the elements that compose the material were determined using X-ray fluorescence and the energy dispersive method (EDX). As previously described ${ }^{46}$, the HPA fractions and their derivatives were separated by high-performance liquid chromatography, and for the identification and quantification of these HPA fractions, gas chromatography was used in performed in conjunction ion with mass spectrometry (GC/MS).

Cytotoxicity assays. MTT [3-(4,5-dimethylthiazol-2-yl)-2,5-diphenyltetrazolium bromide] assay. In a 96-well plate, $3 \times 10^{4}$ cells were seeded in each well, and DEP suspensions were added at 10,50 , and $100 \mu \mathrm{g} / \mathrm{mL}$ concentrations. The cells were exposed at time intervals of $20 \mathrm{~min}, 40 \mathrm{~min}, 1 \mathrm{~h}$ and $2 \mathrm{~h}$. After the cells were exposure to DEP, the wells were washed with PBS. A solution with $2.5 \mathrm{mg} / \mathrm{mL}$ MTT (20\%) was added into each well, and the cells were incubated for $4 \mathrm{~h}$ in a $\mathrm{CO}_{2}$ incubator. After $4 \mathrm{~h}$, the cells in the plate were homogenized with DMSO for $30 \mathrm{~min}$. The plates were read using an enzyme-linked immunosorbent assay (ELISA) reader at 570 and $630 \mathrm{~nm}$. The data for each concentration and time were collected in triplicate and relative O.D were calculated to the control.

Trypan blue assay. In a 12-well plate, $3 \times 10^{4}$ cells were seeded in each well with LHC-9 medium. The cells were exposed to DEP at 50 and $100 \mu \mathrm{g} / \mathrm{mL}$ concentrations for 1 and $2 \mathrm{~h}$. At the end of the experiment, the cells were washed with $1 \times$ PBS and subjected to trypsin. Next, the cells were collected in a sterile tube and centrifuged for $3 \mathrm{~min}$ at $5000 \mathrm{rpm}$. The supernatant was discarded, and the cells were resuspended in a Trypan Blue dye solution. Ten microliters of this dyed cell mixture was placed on a Countess slide (Invitrogen). The data for each concentration and time were collected in triplicate.

BEAS-2B cell transfection. To further investigate the effect of Nrf2 on the autophagic pathway in BEAS-2B cells exposed to DEP, silencing by interference RNA (siRNA) was used to degrade the Nrf2 mRNA to prevent its overexpression and to verify the mechanism through which the autophagy pathway is regulated under these conditions. Lipofectamine RNAiMAX (Invitrogen), siRNA sequences s9394 (Ambion Silencer Select siRNA) and s9491 (Ambion Silencer Select siRNA) and a negative control (Ambion Silencer Select Negative Control) were each utilized at a concentration of $20 \mathrm{nM}^{44,47}$. The negative control (NTC) simulates the same transfection conditions; however, the transfected RNA had a non-significant sequence. To facilitate transfection, siRNA and Lipofectamine were incubated with Opti-MEM medium for $5 \mathrm{~min}$ and added to the cell culture medium as instructed by the manufacturer and incubated for $48 \mathrm{~h}$ to complete the transfections. The groups of BEAS- $2 \mathrm{~B}$ cells are described in Table 3. 
RT-PCR. BEAS-2B and siRNA-transfected BEAS-2B cells were seeded separately in 96-well plates at $3 \times 10^{4}$ cells per well in triplicate for each cell group. After exposure to the treatments (DEP, sulforaphane, EBSS and bafilomycin), total RNA was extracted from the cell pellet using $700 \mu \mathrm{L}$ of Qiazol reagent (Qiagen) with an extraction column (RNeasy Mini kit Qiagen), according to the manufacturer's instructions. The RNA was stored at $-80^{\circ} \mathrm{C}$. The complementary DNA (cDNA) was synthesized using $200 \mathrm{ng}$ of total RNA incubated in the presence of $4 \mu \mathrm{l}$ SuperScript VILO Master Mix (Invitrogen) according to the manufacturer's instructions. All samples were processed for RT-PCR in quadruplicate in a Rotor Gene 3000 instrument (Qiagen). The analysis was performed by calculating the relative quantity of each gene of interest in relation to a housekeeping gene, as indicated in the model described by Livak and Schmittgen ${ }^{48}$ and using the $2^{-\Delta \Delta C T}$ formula. The primer sequences are listed in Table 4. All $2^{-\Delta \Delta \mathrm{CT}}$ values are informed in Supplementary Material.

Statistical analysis. The data distribution was verified by Kolmogorov-Smirnov analysis. The normally distributed variables were analysed by one-way ANOVA, and for the non-normally distributed variables, the non-parametric Kruskal-Wallis test was used. The data are presented in box plot graphs, with median and interquartile range (25\% and 75\%). "Pairwise" and "Holm-Sidak" multiple comparison tests were used to detect differences between groups. The analyses were performed with Sigma Plot and IBM SPSS 21.0 statistical software. The level of significance was considered to be $\mathrm{p} \leq 0.05$.

Western blotting. BEAS-2B and siRNA-transfected BEAS-2B cells were seeded separately in 6-well plates, containing $2 \times 10^{5}$ cells per well, in duplicate per group. Following cell exposure, the proteins were collected with RIPA extraction buffer in the presence of protease inhibitors and phosphatase inhibitors (Sigma Aldrich). Total protein was quantified by the Bradford method, and $50 \mu \mathrm{g}$ of protein was used for electrophoresis on a $12 \%$ polyacrylamide gel. After the proteins were transferred to a PVDF membrane, the membrane was blocked in non-fat dry milk diluted to $5 \%$ in PBS with $0.1 \%$ Tween for $1 \mathrm{~h}$. After blocking, the membrane was incubated overnight with antibodies against $\beta$-actin (Sigma 1:10000), Nrf2 (Abcam 1:1000), LC3B (Abcam 1:1000) and p62 (Abcam 1:1000). Next, the membrane was washed 3 times with PBS-Tween and incubated with goat anti-rabbit HRP secondary antibody $(1: 1000)$ for $1 \mathrm{~h}$. The membrane was then revealed by chemiluminescence using an ECL kit (GE Healthcare Life Sciences) on an ImageQuant ${ }^{\mathrm{TM}}$ LAS 4000 apparatus. Every image was captured after 10-30 seconds of exposure. The proportion of each protein was obtained by the densitometry method. ImageJ software was used to analyse the intensity of the bands. On the basis of the band area values, the proteins of interest were normalized to $\beta$-actin expression (area of interest protein/ $\beta$-actin area). After normalization, the ratio $(\mathrm{R})$ of each treatment was calculated according to the value of the untreated cell (treatment/ untreated, in which untreated cell $=1$ ). Thus, an increase in the protein is considered when $\mathrm{R}>1$. Each analysis was performed in duplicate.

siRNA immunofluorescence assay. BEAS-2B and siRNA-transfected BEAS-2B cells were seeded separately in 24 -well plates at $2 \times 10^{5}$ per well in duplicate per group with coverslips in the wells for use in microscopy. After exposure, the cells were fixed with $100 \%$ methanol for $15 \mathrm{~min}$ at $-20^{\circ} \mathrm{C}$ and then washed 3 times with PBS for $10 \mathrm{~min}$ at $4^{\circ} \mathrm{C}$. For permeabilization, the samples were incubated for $10 \mathrm{~min}$ with PBS with $0.2 \%$ Triton X-100. Next, the samples were blocked for $1 \mathrm{~h}$ with $5 \% \mathrm{BSA}$ and incubated overnight at $4{ }^{\circ} \mathrm{C}$ in a humid chamber with primary antibodies against LC3B (Cell Signaling 1:100) and Nrf2 (Abcam 1:50) for double staining. On the following day, the samples were incubated with secondary antibodies (Alexa Fluor-488 and Alexa Fluor-546, 1:200) for $1 \mathrm{~h}$ in a humid chamber at room temperature and then incubated with 1:200 DAPI for $15 \mathrm{~min}$. The images were captured under a $40 \times$ objective lens with Image Pro Plus software. After being acquired, the photos were merged by ImageJ software to combine the green, red and blue markers. The chosen fields were augmented $2 \times$. Antibodies control test is available in Supplementary Material.

Received: 4 September 2019; Accepted: 4 February 2020;

Published online: 28 February 2020

\section{References}

1. Maynard, R. L. The effects on health of ambient particles: time for an agonizing reappraisal? Cell Biol. Toxicol. 31, 131-147 (2015).

2. Lima, T. M. et al. $\mathrm{pH}$ in exhaled breath condensate and nasal lavage as a biomarker of air pollution-related inflammation in street traffic-controllers and office-workers. Clin. 68, 1488-1494 (2013).

3. Rodríguez-Cotto, R. I. et al. Particle pollution in Rio de Janeiro, Brazil: increase and decrease of pro-inflammatory cytokines IL-6 and IL-8 in human lung cells. Env. Pollut. 194, 112-120 (2014).

4. de Brito, J. M. et al. Acute exposure to diesel and sewage biodiesel exhaust causes pulmonary and systemic inflammation in mice. Sci. Total. Environ. 628, 1223-1233 (2018)

5. Carvalho-Oliveira, R. et al. Anti-oxidants reduce the acute adverse effects of residual oil fly ash on the frog palate mucociliary epithelium. Env. Res. 98, 349-354 (2005).

6. Li, N., Wang, M., Oberley, T. D., Sempf, J. M. \& Nel, A. E. Comparison of the Pro-Oxidative and Proinflammatory Effects of Organic Diesel Exhaust Particle Chemicals in Bronchial Epithelial Cells and Macrophages. J. Immunol. 169, 4531-4541 (2002).

7. Mazzoli-Rocha, F., Fernandes, S., Einicker-Lamas, M. \& Zin, W. A. Roles of oxidative stress in signaling and inflammation induced by particulate matter. Cell Biol. Toxicol. 26, 481-498 (2010).

8. Deng, X., Rui, W., Zhang, F. \& Ding, W. PM2.5 induces Nrf2-mediated defense mechanisms against oxidative stress by activating PIK3/AKT signaling pathway in human lung alveolar epithelial A549 cells. Cell Biol. Toxicol. 29, 143-157 (2013).

9. Johansen, T. \& Lamark, T. Selective autophagy mediated by autophagic adapter proteins. Autophagy. 7, 279-296 (2011).

10. Hale, A. N., Ledbetter, D. J., Gawriluk, T. R. \& Rucker, E. B. Autophagy: regulation and role in development. Autophagy. 9, 951-972 (2013).

11. Lippai, M. \& Szatmári, Z. Autophagy-from molecular mechanisms to clinical relevance. Cell Biol. Toxicol. 33, 145-168 (2017).

12. Bai, R. et al. Comparative study of the effects of PM1-induced oxidative stress on autophagy and surfactant protein B and C expressions in lung alveolar type II epithelial MLE-12 cells. Biochim. Biophys. Acta. 1860, 2782-2792 (2016). 
13. Zhou, Z. et al. The effects of autophagy on vascular endothelial cells induced by airborne PM2.5. Env. Sci. 66, 182-187 (2018).

14. Long, F., Jiang, H., Yi, H., Su, L. \& Sun, J. Particulate matter 2.5 induced bronchial epithelial cell injury via activation of 5 '-adenosine monophosphate-activated protein kinase-mediated autophagy. J. Cell Biochem. 120, 3294-3305 (2019).

15. Seriani, R. et al. Enriched inorganic compounds in diesel exhaust particles induce mitogen-activated protein kinase activation, cytoskeleton instability, and cytotoxicity in human bronchial epithelial cells. Exp. Toxicol. Pathol. 67, 323-329 (2015).

16. Steiner, S., Bisig, C., Petri-Fink, A. \& Rothen-Rutishauser, B. Diesel exhaust: current knowledge of adverse effects and underlying cellular mechanisms. Arch. Toxicol. 90, 1541-1553 (2016).

17. Wichmann, H. E. Diesel Exhaust Particles. Inhalation Toxicology. 19, 241-244 (2007).

18. Madl, P. Exposure to Nano-Sized Particles and the Emergence of Contemporary Diseases with a Focus on Epigenetics. In: Khare, M., editor. Air Pollution: Monitoring, Modelling and Health. InTech 305-336 (2013).

19. Takizawa, H. Impact of air pollution on allergic diseases. Korean J. Intern. Med. 26, 262-273 (2011).

20. Jain, A. K., Bloom, D. A. \& Jaiswal, A. K. Nuclear import and export signals in control of Nrf2. J. Biol. Chem. 280, 29158-2968 (2017).

21. Itoh, K. et al. Chiba, T. An Nrf2/small Maf heterodimer mediates the induction of phase II detoxifying enzyme genes through antioxidant response elements. Biochem. Biophys. Res. Commun. 18, 313-322 (1997).

22. Leclercq, B. et al. Air pollution-derived PM2.5 impairs mitochondrial function in healthy and chronic obstructive pulmonary diseased human bronchial epithelial cells. Env. Pollut. 243, 1434-1449 (2018).

23. Radan, M. et al. In vivo and in vitro evidence for the involvement of Nrf2-antioxidant response element signaling pathway in the inflammation and oxidative stress induced by particulate matter (PM10): the effective role of gallic acid. Free. Radic. Res. 53, 210-225 (2018).

24. Cattani-Cavalieri, I. et al. Acute Exposure to Diesel-Biodiesel Particulate Matter Promotes Murine Lung Oxidative Stress by Nrf2/ HO-1 and Inflammation Through the NF-kB/TNF- $\alpha$ Pathways. Inflammation. 42, 526-537 (2018).

25. Pajares, M. et al. Transcription factor NFE2L2/NRF2 is a regulator of macroautophagy genes. Autophagy. 12, 1902-1916 (2016).

26. Komatsu, M. et al. The selective autophagy substrate p62 activates the stress responsive transcription factor Nrf2 through inactivation of Keap1. Nat. Cell Biol. 12, 213-223 (2010).

27. Lau, A. et al. Noncanonical Mechanism of Nrf2 Activation by Autophagy Deficiency: Direct Interaction between Keap1 and p62. Mol. Cell Biol. 30, 3275-3285 (2010).

28. Komatsu, M. et al. Homeostatic levels of p62 control cytoplasmic inclusion body formation in autophagy-deficient mice. Cell. 131, $1149-1163$ (2007).

29. Seriani, R. et al. Diesel exhaust particulates affect cell signaling, mucin profiles, and apoptosis in trachea explants of Balb/C mice. Env. Toxicol. 30, 1297-1398 (2015).

30. Lai, C. H. et al. Protein oxidation and degradation caused by particulate matter. Sci. Rep. 6, 33727 (2016).

31. Wang, Y. et al. Roles of ROS, Nrf2, and autophagy in cadmium-carcinogenesis and its prevention by Sulforaphane. Toxicol. Appl. Pharmacol. 353, 23-30 (2018).

32. Son, Y. O., Pratheeshkumar, P., Divya, S. P., Zhang, Z. \& Shi, X. Nuclear factor erythroid 2-related factor 2 enhances carcinogenesis by suppressing apoptosis and promoting autophagy in nickel-transformed cells. J. Biol. Chem. 292, 8315-8330 (2017).

33. Shah, P. et al. Arsenic Induces p62 Expression to Form a Positive Feedback Loop with Nrf2 in Human Epidermal Keratinocytes: Implications for Preventing Arsenic-Induced Skin Cancer. Molecules. 22, 194-206 (2017).

34. Lau, A. et al. Arsenic inhibits autophagic flux, activating the Nrf2-Keap1 pathway in a p62-dependent manner. Mol. Cell Biol. 33, 2436-2446 (2013).

35. Zhu, L. et al. Regulation of Cigarette Smoke (CS)-Induced Autophagy by Nrf2. PLoS One. 8, e55695 (2013).

36. Kapuy, O., Papp, D., Vellai, T., Bánhegyi, G. \& Korcsmáros, T. Systems-Level Feedbacks of NRF2 Controlling Autophagy upon Oxidative Stress Response. Antioxid. 5, 39-56 (2018).

37. Zhou, F. et al. Effects of diesel exhaust particles on microRNA-21 in human bronchial epithelial cells and potential carcinogenic mechanisms. Mol. Med. Rep. 12, 2329-2335 (2015).

38. Matsuo, M., Shimada, T., Uenishi, R., Sasaki, N. \& Sagai, M. Diesel exhaust particle-induced cell death of cultured normal human bronchial epithelial cells. Biol. Pharm. Bull. 26, 438-447 (2003).

39. Li, N. et al. Ultrafine particulate pollutants induce oxidative stress and mitochondrial damage. Env. Health Perspect. 111, 455-460 (2003).

40. Seriani, R. et al. Human bronchial epithelial cells exposed in vitro to diesel exhaust particles exhibit alterations in cell rheology and cytotoxicity associated with decrease in antioxidant defenses and imbalance in pro- and anti-apoptotic gene expression. Env. Sci. Pollut. Res. Int. 23, 9862-9870 (2016).

41. D’Arcy, M. S. Cell death: a review of the major forms of apoptosis, necrosis and autophagy. Cell Biol. Int. 43, 582-592 (2019).

42. Wierzbicka, A. et al. Detailed diesel exhaust characteristics including particle surface area and lung deposited dose for better understanding of health effects in human chamber exposure studies. Atmos. Environment. 86, 212-219 (2014).

43. Klionsky, D. J. et al. Guidelines for the use and interpretation of assays for monitoring autophagy (3rd edition. Autophagy. 12, 1-222 (2016).

44. Lee, Y. J. \& Lee, S. H. Sulforaphane induces antioxidative and antiproliferative responses by generating reactive oxygen species in human bronchial epithelial BEAS-2B cells. J. Korean Med. Sci. 26, 1474-1482 (2011).

45. Laks, D. et al. Composition of diesel particles influences acute pulmonary toxicity: An experimental study in mice. Inhal. Toxicol. 20, 1037-1042 (2008).

46. Vasconcellos, P. C. et al. Seasonal Variation of n-Alkanes and Polycyclic Aromatic Hydrocarbon Concentrations in PM10 Samples Collected at Urban Sites of São Paulo State, Brazil. Water, Air, Soil. Pollution. 222, 325-336 (2011).

47. Su, S., Yang, X. \& Omiecinski, C. J. Intronic DNA elements regulate Nrf2 chemical responsiveness of the human microsomal epoxide hydrolase gene (EPHX1) through a far upstream alternative promoter. Biochim. Biophys. Acta. 1839, 493-505 (2014).

48. Livak, K. J. \& Schmittgen, T. D. Analysis of relative gene expression data using real-time quantitative PCR and the 2(-Delta Delta C(T)) Method. Methods. 25, 402-408 (2001).

\section{Acknowledgements}

This work was supported by Brazil's Sao Paulo Research Foundation (FAPESP), under grant number 2016/027824 , and the Coordination for Improvement of Higher Education (CAPES).

\section{Author contributions}

D.P.F. - Master's degree student: conducted cell culture exposures, RT-PCR, Western blotting and immunofluorescence experiments, analysed the data and conceived the main ideas of the article and the text; R.L.N. and K.Y.: helped with cell culture exposure and cytotoxicity assays; Matsuda M.: expert researcher in mRNA analyses, contributed to RT-PCR standardization; M.S.J.: expert researcher in protein analyses, contributed to Western blotting procedures; W.R.T.: expert professor in immunofluorescence and immunohistopathology; P.R.C: conducted DEP collection; P.C.V. and D.C.A.P. conducted the DEP organics analysis; R.C.O.: conducted EDX and statistical analyses; P.H.N.S. and T.M. expert professors in air pollution and airway implications; 
Macchione M: project coordinator, conceived the main idea of the study, contributed to the data analysis and manuscript writing. All authors reviewed the manuscript.

\section{Competing interests}

The authors declare no competing interests.

\section{Additional information}

Supplementary information is available for this paper at https://doi.org/10.1038/s41598-020-59930-3.

Correspondence and requests for materials should be addressed to D.P.F.

Reprints and permissions information is available at www.nature.com/reprints.

Publisher's note Springer Nature remains neutral with regard to jurisdictional claims in published maps and institutional affiliations.

(c) (i) Open Access This article is licensed under a Creative Commons Attribution 4.0 International License, which permits use, sharing, adaptation, distribution and reproduction in any medium or format, as long as you give appropriate credit to the original author(s) and the source, provide a link to the Creative Commons license, and indicate if changes were made. The images or other third party material in this article are included in the article's Creative Commons license, unless indicated otherwise in a credit line to the material. If material is not included in the article's Creative Commons license and your intended use is not permitted by statutory regulation or exceeds the permitted use, you will need to obtain permission directly from the copyright holder. To view a copy of this license, visit http://creativecommons.org/licenses/by/4.0/.

(C) The Author(s) 2020 